\title{
Editorial
}

\section{Recasting the Narrative: Adapting and Leading the Transition to New Roles}

As I write this editorial, I am attending SXSW EDU ${ }^{1}$ in Austin-not your average library conference as it focuses on trends in education more broadly (higher education and $\mathrm{K}-12$ ) and the impacts or opportunities that emerging technologies present. My primary motivation for attending was to gain a new perspective and challenge well-ingrained mental models - in truth, to get out of a rut. The sessions definitely aligned with trends we see in education. There were several sessions on data visualization and using it for purposes of assessment and patriating stakeholders; Not surprisingly, much attention was given to media literacy and fake news, particularly as it pertains to educating students of all levels about being discerning consumers of information and advocating critical inquiry; I also attended presentations on democracy and citizenship, free speech on campus (balancing safety and cultural awareness), empowering student activists, and engaging disadvantaged students and specialized groups such as veteran students.

It was fascinating to see the influence of social movements, political rhetoric, and technology on educational efforts and priorities. It brought back to me that librarians are in a position to promote social change and be fearless in their engagement on issues of equity and access and defense of information integrity and transparency. Libraries are, by virtue of their fundamental mission, well-equipped to address these issues.

This experience was a great prelude to the ACRL 2019 conference. When we talk about recasting the narrative, we talk about the roles we play and what our jobs look like. The impact of technology (and other factors) on librarians and on the work they do is evident in the research on job postings. Since 1991 (the year the Internet went public), there have been numerous studies of job postings in academic libraries examining how the positions and responsibilities and the attendant KSAs (knowledge, skills, abilities) have changed. Therese Triumph and Penny Beile co-authored a representative study that examined the trends in job titles and provided an indication of the rapid change in the profession and the impact that technology has had. Selected position categories from 1996 included:

- Electronic/technical

- Systems

- Special collections

- Preservation

- Instruction

- Government Documents ${ }^{2}$

According to the same study, the positions with titles emerging by 2011 were:

- Digital

- Archivist/Curator

- Electronic Resources

- Assessment 
- Scholarly Communication

- Metadata ${ }^{3}$

A quick scan of the positions we see in 2019 includes:

- Research data management

- Data analysis

- Maker

- Evidence based

- Usability

- Teaching and Learning

Just the brief examination of the change in librarian positions demonstrates a definite shift to engaging in the formation of information through analysis or assessment, data-driven practice, and scholarly publication. It is an acknowledgment that librarians are not just custodians of information but are also creators of information. It is not that this is a new role-but that it looks different now and the recognition of the importance of these efforts has been brought into the spotlight.

It is evident that change is a way of life for academic librarians. Technology, policy, economics, and social drivers are constantly influencing higher education and, in turn, academic libraries. However, more fundamentally, we also need to consider how our roles as librarians contribute to higher education, to our communities, and to society as a whole.

A recent scholarly blog addressed these priorities and directions very effectively. ${ }^{4}$ Lettie Conrad asserts, "Prioritization is the name of the game these days, as technological innovation and ever-changing information practices accelerate the rate of change in our industry. We simply cannot respond to every new initiative and headline." There are a lot of significant drivers affecting higher education and academic libraries but there is also a lot of noise-loud and insistent demands for attention or action that may or may not be within the scope of our mission. From the same blog post, Alice Meadows silences this noise with "This means being brutally honest about the purpose of your organization: why does it exist? who do you serve? what does it mean for your priorities, past, present, and future?"

The questions that Meadows poses may seem obvious, but they are also fundamental. It's easy to get stuck in a cycle-focusing on tasks rather than the needs of your constituents. Being mindful of these values and intentional in one's efforts, particularly when there is so much noise and so many competing demands, is challenging. Choices have to be made-about what is important and what is core to the mission-because resources of time, money, effort, and even space, are finite (and growing scarcer). A responsiveness to changing landscapes is particularly difficult, especially when there is continued focus on what the job is vs. what the need is.

There are a couple of classic texts that can provide a solution and a model for dealing with the state of constant change in academic libraries and higher education more broadly. Peter Senge offered the concept of the Learning Organization ${ }^{5}$ almost 30 years ago (following it up with the bestseller, Fifth Discipline) but it still has relevance today and into the future. It is predicated on the idea that learning organizations are those where learning is constantwhere they are asking questions, taking risks, making mistakes, and learning from them. These organizations are masters at adapting to their environment and transforming themselves to meet the ongoing mission and the needs of those they serve. It has been argued that academic libraries typify these learning organizations. 
Along the same lines, academic librarians are well-positioned to embody these values as individuals. I have written on internal consultants and change agents in previous editorials. This is an idea that I find particularly relevant and useful as it promotes flexibility in the position as well as responsiveness to the environment and to the changing needs of the organization and its clientele. The idea of a consultant-someone who identifies what is needed to achieve the goals of an organization-strikes me as a valuable way for librarians to approach the continual changes to the profession. It requires a commitment to learning and self-development, awareness about organizational needs and engagement opportunities, a willingness to take risks and learn from mistakes, and a focus on impact over tasks. Just as higher education is being torn down and rebuilt by various forces, academic libraries are being transformed - and the roles that academic librarians take on, however they may be titled, must be flexible enough to adapt to these changes to continue to meet their mission.

\section{Notes}

1. SXSW Edu Conference and Festival, March 4-7, 2019 Austin, TX, https://www.sxswedu.com/.

2. Therese F. Triumph and Penny M. Beile. "The Trending Academic Library Job Market: An Analysis of Library Position Announcements from 2011 with Comparisons to 1996 and 1988." College \& Research Libraries 76, no. 6 (2015): 716-739, https://doi.org/10.5860/crl.76.6.716.

3. Ibid, 723.

4. Ann Michael, "Ask The Chefs: Prioritizing Organizational Choices," The Scholarly Kitchen (February 26, 2019), available online at https://scholarlykitchen.sspnet.org/2019/02/26/ask-chefs-prioritizing-choices.

5. Peter M. Senge, "The Fifth Discipline, the Art and Practice of the Learning Organization." Performance Improvement 30, no. 5 (1991): 37, https://doi.org/10.1002/pfi.4170300510. 